\title{
Train design features affecting boarding and alighting of passengers
}

Roselle Thoreau, Catherine Holloway, Gurvir Bansal, Kuldeep Gharatya, Tyng-Rong Roan, Nick Tyler,

\section{Abstract}

Accurately predicting train dwell time is critical to running an effective and efficient service. With high-density passenger services large numbers of passengers must be able to board and alight the train quickly - and within scheduled dwell times. Using a specially constructed train mock-up in a pedestrian movement laboratory the experiments outlined in this paper examine the impact of train carriage design factors such as door width, seat type, platform edge doors and horizontal gap on the time taken by passengers to board and alight. The findings illustrate that the effectiveness of design features depends on whether there are a majority of passengers boarding or alighting. An optimum door width should be between $1.7 \mathrm{~m}$ and $1.8 \mathrm{~m}$. The use of a central pole and platform edge doors produced no major effects, but a $200 \mathrm{~mm}$ horizontal gap could increase the movement of passengers. There is no clear effect of the type of seats and neither the standbacks between 50 $\mathrm{mm}, 300 \mathrm{~mm}$ and $500 \mathrm{~mm}$. Further research will look for the relationship between the dwell time and the characteristics of passengers such as personal space.

Keywords: commuter rail; flow; passenger movement; train dwell time; transport and pedestrian studies; transportation engineering

\section{Introduction}

The duration of time when a train stops in a station (dwell time) is critical to train scheduling. This duration has implications right across a service. When train dwell time can be predicted accurately it can improve the punctuality of service and enables modellers to forecast run times and service capacity [1]. This is especially valuable for complex train systems and high density stations. When delays occur to a single train departing from a station, this can result in a knock-on effect across the whole of the service. This has been shown not only in freight services in which delays are associated to loading/unloading, train connections or fueling [2], but also in passenger services [3-5]. For passenger train services delays can be caused not only by external factors such as weather, track or signal failure but on dwell time at the station. This dwell time is dependent not only on the number of passengers boarding or alighting but additionally on the gap between the train and platform as well as the design and layout of the train itself.

Every day circa 4.25 million trips are taken using the London Underground, with 400,000 people alone starting their journey between 8am and 9am [6]. One of the busiest stations, Oxford Circus has 125,000 people enter and 136, 000 exit it each day. Many London Underground lines operate 
one train every 2-3 minutes during peak time. Given the amount of people needing to board or alight the train at each station and the length of time a train can stay in the station to maintain the line frequency, the movement of passengers needs to be as fast and as efficient as possible.

The dwell time is a key variable which alters service frequency, and reliability. The occupancy time within a station is calculated using the train unblocking, doors opening, passenger boarding and alighting, doors closing and train dispatching dwell [7]. The time it takes passengers to board and alight from a train makes up a significant proportion of the time a train spends at a station and therefore has great impact on train frequency and capacity of the network. Much of the time a train spends at a station is due to passenger boarding and alighting, which could be observed directly on the platform [810]. This is particularly true in busy metro and suburban stations. The faster and more efficient passenger movement on and off the train can be made, the faster the end-to-end run times that can be achieved. This will increase the capacity of the line. When the required capacity is low, trains are generally programmed to stop at a station for a fixed amount of time, more than what is required for passengers to board and alight. When required capacity increases additional dwell time is often required depending on the direction and amount of boarding and alighting movements as well as internal train layout [11]

Research has been completed looking at the speed and behaviour of passengers on trains and within stations [12-18] but little research to date has examined the impact that train carriage design plays on passenger movement. In a study of boarding and alighting, Lin and Wilson [10] reported that knowledge of crowding and congestion on board the train would improve flow rate models. To manage crowds on platform, [19] found that platform edge doors (PEDs) had no important impact in the boarding and alighting times, but the behavior of passengers changed by queuing at the side of the doors rather than in the front. Research into rail and metro train dwell times shows that a step height between train and platform of $50 \mathrm{~mm}$ increases the number of passenger movements, reaching a maximum flow of 1.42 pass/s for a door $1.8 \mathrm{~m}$ width [20]. Moreover, [21] reported that a small step height reduces the dwell time in $8 \%$. This is particularly key for those passengers encumbered by luggage or pushchairs, in which passengers boarding (4.13 s) spent more time than passengers alighting (3.68 s) [22].

Boarding and alighting time is usually calculated using regression models $[11,13,14]$, as a function of the layout of the train (e.g. door width), distribution and number of passengers, and the behaviour of boarding and alighting. More recently, laboratory experiments have been carried out to understand how different variables such as door width, platform width and layout of trains impact upon boarding and alighting times [23-26]. In particular, [25] stated that a vertical gap of $150 \mathrm{~mm}$ could reduce the boarding and alighting times. These results could be considered as going in the opposite direction with [22] in relation to accessibility. Similarly, [24] reported that the optimum door width should be $1.8 \mathrm{~m}$ with a vestibule setback of $800 \mathrm{~mm}$, which is different from the optimum door width of $1.65 \mathrm{~m}$ in [25]. 
Despite of the research done to optimize the vehicle and platform designs, London Underground commissioned University College London (UCL) to carry out a series of experiments using a specially constructed mock up tube train carriage installed at the UCL Pedestrian Accessibility Movement and Environment Laboratory (PAMELA). The mock up carriage permits a variety of configurations which can be tested. The aim was to design a more effective train. The questions which this study aimed to answer were (1) would a $1.6,1.7$ or $1.8 \mathrm{~m}$ door width be best for passenger boarding and alighting rates? (2) Does the vestibule standback affect passenger boarding and alighting rates and passenger distribution in the carriage? (3) Does the type of seating affect passenger boarding and alighting rates and passenger distribution in the carriage? (4) Does the presence of a central vestibule pole affect passenger boarding and alighting rates? (5) Do the presence of platform edge doors and an increased horizontal gap affect passenger boarding and alighting rates?

This paper is composed of five sections, including this one. In the second Section the method of this paper is described. Next, in the third Section the scenarios of simulation are presented. In the fourth Section a complete discussion is provided. Finally, in the fifth Section the conclusions are delivered.

\section{Method}

The method consisted of four stages. Firstly, the variables were selected according to one of the three groups reported in [27]: physical (e.g. door width), spatial (e.g. seat type), and operational (e.g. demand). The selected variables were based on the new rolling stock for the London Underground trains obtained as part of a complete research project in collaboration with Transport for London (see Table 1).

The features tested were door width, standback, seat type, central grab pole, platform edge doors (PED) and horizontal gap (Table 1). The door widths tested were $1.6 \mathrm{~m}, 1.7 \mathrm{~m}$ and $1.8 \mathrm{~m}$. Standback refers to the area between the edge of the doors and the end of the vestibule as illustrated in Figure 2. The standback lengths tested were $50 \mathrm{~mm}, 300 \mathrm{~mm}$ and $500 \mathrm{~mm}$. The seat types tested were tip-up seats and perch seats. A horizontal gap of $75 \mathrm{~mm}$ was tested across all the other design features but an additional test of a horizontal gap of $200 \mathrm{~mm}$ was also tested. The presence or absence of a central pole was tested across ass door widths and with a standback of $300 \mathrm{~mm}$. The effect of platform edge doors (PED) were tested with a horizontal gap of $75 \mathrm{~mm}, 150 \mathrm{~mm}$ and $200 \mathrm{~mm}$. 
Table 1: Selected variables for the experiments

\begin{tabular}{|l|l|l|l|l|}
\hline & Width $\mathbf{( m )}$ & $\begin{array}{l}\text { Standback } \\
\mathbf{( m m})\end{array}$ & Seat Type & $\begin{array}{l}\text { Horizontal } \\
\text { gap } \\
\mathbf{( m m}\end{array}$ \\
\hline Door Width & $\begin{array}{l}1.6,1.7 \& \\
1.8\end{array}$ & 300 & Tip-up & 75 \\
\hline Standback & 1.7 & $\begin{array}{l}50,300 \& \\
500\end{array}$ & Tip-up & 75 \\
\hline Seat Type & 1.7 & 50 & $\begin{array}{l}\text { Tip-up \& } \\
\text { Perch }\end{array}$ & 75 \\
\hline $\begin{array}{l}\text { PED and } \\
\text { Horizontal } \\
\text { Gap }\end{array}$ & 1.7 & 50 & Tip-up & $\begin{array}{l}\text { Without PED: } \\
75 \& 200 \\
\text { With PED: 75, } \\
150 \& 200\end{array}$ \\
\hline $\begin{array}{l}\text { Central } \\
\text { Pole }\end{array}$ & $\begin{array}{l}1.6,1.7 \& \\
1.8\end{array}$ & 300 & Tip-up & 75200 \\
\hline
\end{tabular}

Secondly, the experiments took place at the PAMELA facility at UCL. PAMELA is a multisensory pedestrian environment laboratory, consisting of a large pedestrian area, controlled to provide different topographies, vertical and horizontal obstacles, different lighting, noise conditions. Full-scale mockups of vehicles with surround sound and multi angle recording can be built inside the lab and movement on the platform can be filmed and tracked in real time.

For this experiment a full-size mock-up of a single carriage of the proposed two-double door train was constructed, based on drawings supplied by London Underground and designed to permit the changes in the features to be tested (see Figure 1 and Figure 2). A horizontal gap between the train and the platform could be altered and platform edge doors could be added. An ambisonic sound environment was created for the experiments to mimic station sounds including the sound of a train arriving at the station, public address announcements and the sounds of the doors opening and closing. Cameras were positioned directly above the carriage doors, as well as in positions so that the inside of the whole carriage was captured as well as the whole of the station platform. This was so that the movement of any of the participants could be captured during the whole experiment regardless of where they were, or moved to, on the train or the platform. 

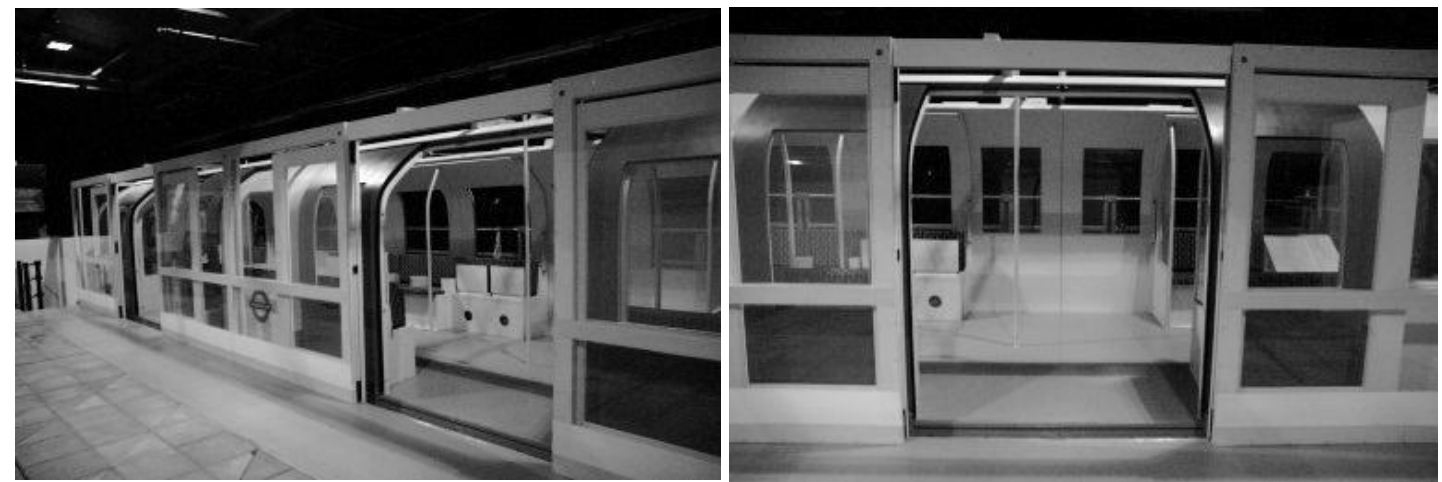

Figure 1: Sample images of the mock-up train carriage at the PAMLEA facility with Platform Edge Doors (PEDs)

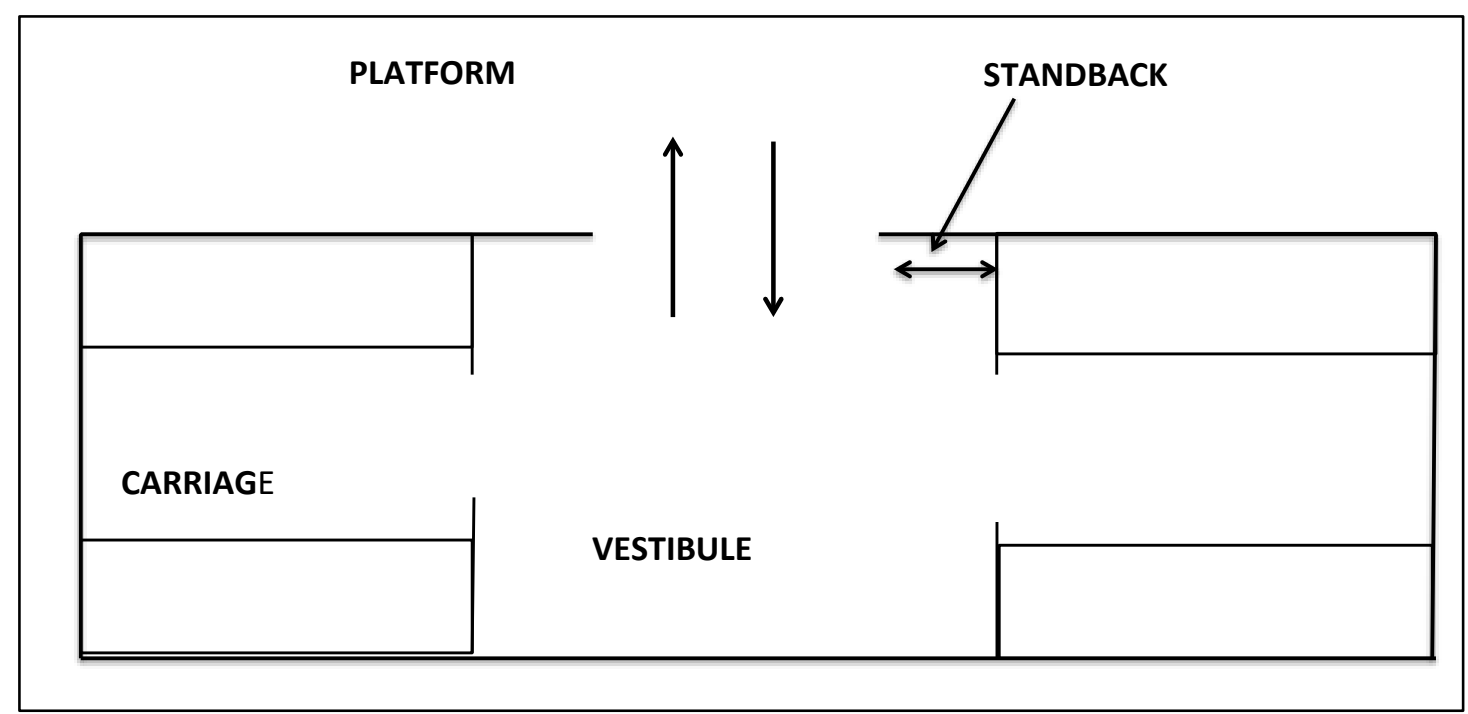

Figure 2: Birds Eye View of a train carriage showing vestibule standback

Thirdly, for the different scenarios a total of 110 participants were recruited, with a mix of ages and gender. A convenience sample was used of people of self-reported being regular tube users. Participants were given a number, a bid color and a red hat and a white hat. Before each experiment there was an announcement telling participants who should alight, board or stay on board the train based on their assigned numbers. Participants wore their red hat when boarding and their white hat when alighting to make the visual aspect of the data extraction and analysis easier. Variations of the number of people boarding and alighting were made across the experiments. An experiment 'run' consisted of the participants being assembled in their starting positions, and the doors of the train closed. The sound system was started, which initiated the clock time for the run, and the passengers heard the train arriving, decelerating and stopping. The doors were opened, the passengers boarded/alighted as per their instructions, the doors were closed and the train was heard to leave the station. Routine passenger announcements were made during the run according to normal practice on London Underground. A combined total of 465 experimental runs were carried out with the various train configurations (totaling 92 design parameter combinations) and scenarios resulting in 20,000 individual passenger 
movements. The mock-up carriage was modeled after a potential new design carriage with two doors. The crush load capacity for this carriage was 109 people, giving an average of 7 people per metre squared inside the train.

The experiment runs were based on a set of scenarios which represented different boarding/alighting conditions; equal boarding and alighting, majority boarding, and majority alighting (see Figure 3 ). Three passenger movement scenarios are presented here. (1) Equal Passenger Boarding and Alighting. In this scenario 40 people boarded, 40 people alighted and 30 people remained on the train. (2) Majority of Passengers Alighting. In this scenario 20 people boarded, 80 people alighted and 10 people remained on the train. (3) Majority of Passengers Boarding. In this scenario consisted of 80 people boarding, 20 people alighting and 10 people remaining on the train.

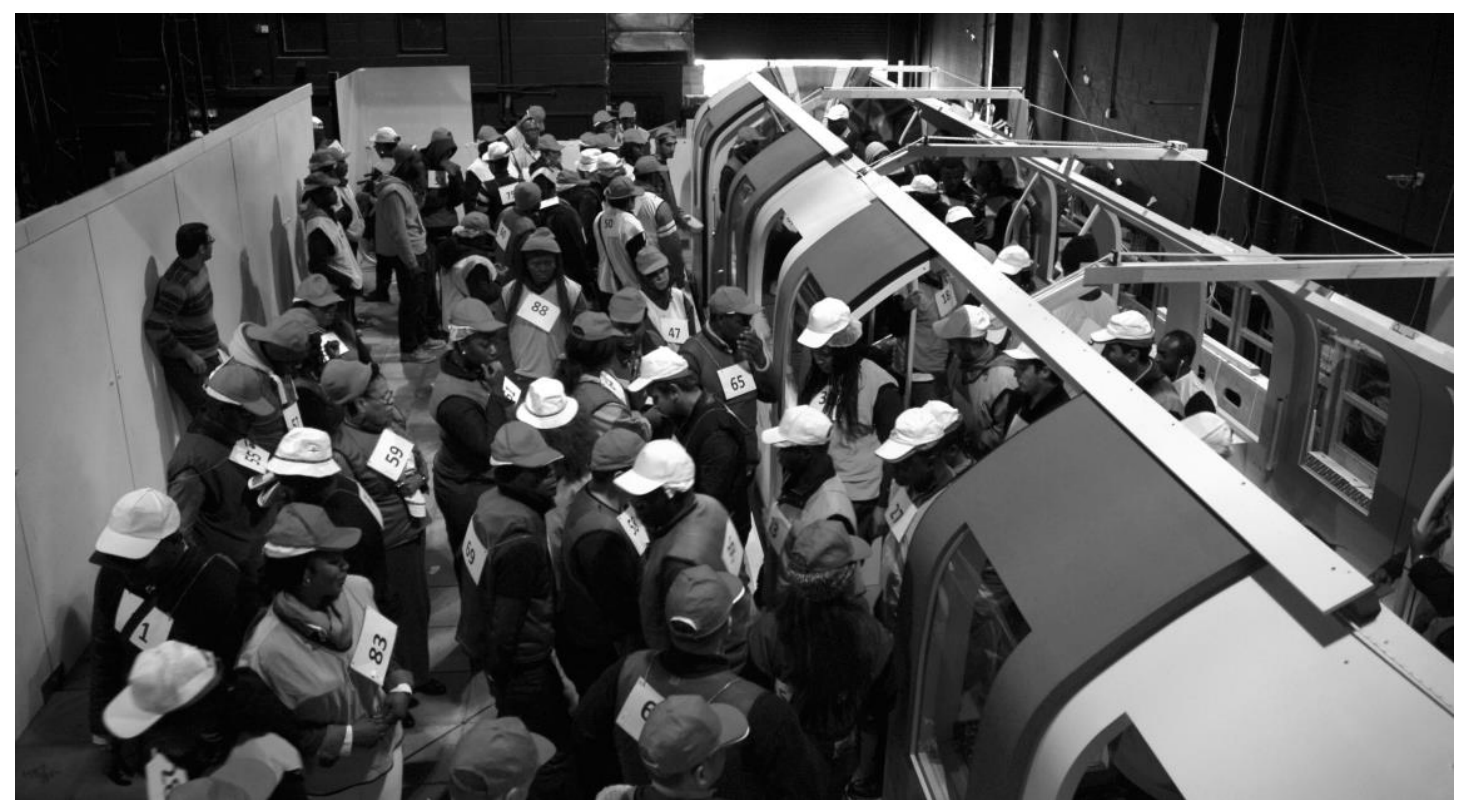

Figure 3: View of the mock-up train carriage showing participants boarding and alighting

Fourthly, the data was extracted from the video footage using Observer (version 9.0) and analysed using Java analysis tools. Each of the experimental runs was analysed to measure when the doors began opening, when each person boarded or alighted the carriage, when the doors were fully opened, when the doors began closing and when they were fully closed. The Door Open Times was calculated from the moment the doors began to open until the moment they were fully closed. Passenger flow rates were obtained over 2.5 second periods between these times.

Each scenario was compared in terms of number of passengers boarding or alighting, and the flow throughout doors. In addition, the Level of Service (LOS) [28] was used. The LOS is a qualitative indicator to measure the degree of congestion and conflict of passengers in walkways, stairs and queue areas. In walkways, the LOS goes from a Level A (free flow lower than 
0.38 passengers per second per meter) to a Level $F$ (flow higher than 1.36 pass/s-m), where LOS =E is equal the capacity (flow between 1.1 pass/s-m and $1.36 \mathrm{pass} / \mathrm{s}-\mathrm{m})$. Therefore, if the change in design improved the LOS, then it could be considered a better design. $A$ LOS $=F$ should be avoided in all situations.

\section{Results}

\subsection{Door Width}

In the equal passenger boarding scenario, the door width of $1.7 \mathrm{~m}$ performed best. This is illustrated in Figure 4. All passengers had boarded and alighted in less than 40 seconds. After 20 seconds the $1.7 \mathrm{~m}$ door width had resulted in 10 more people having boarded or alighted than the $1.6 \mathrm{~m}$ or $1.8 \mathrm{~m}$ door widths. In addition, all cases presented a LOS lower than F. In the case of $20 \mathrm{~s}$ the $1.7 \mathrm{~m}$ reached a flow of $0.66 \mathrm{pass} / \mathrm{s}-\mathrm{m}$ (LOS C), whilst the $1.6 \mathrm{~m}$ and $1.8 \mathrm{~m}$ reached a flow of 0.53 pass $/ \mathrm{s}-\mathrm{m}$ (LOS B) and 0.47 pass $/ \mathrm{s}-\mathrm{m}$ (LOS B), respectively. Therefore, the $1.7 \mathrm{~m}$ presented a higher flow without affecting negatively the congestion and conflicts of passengers.

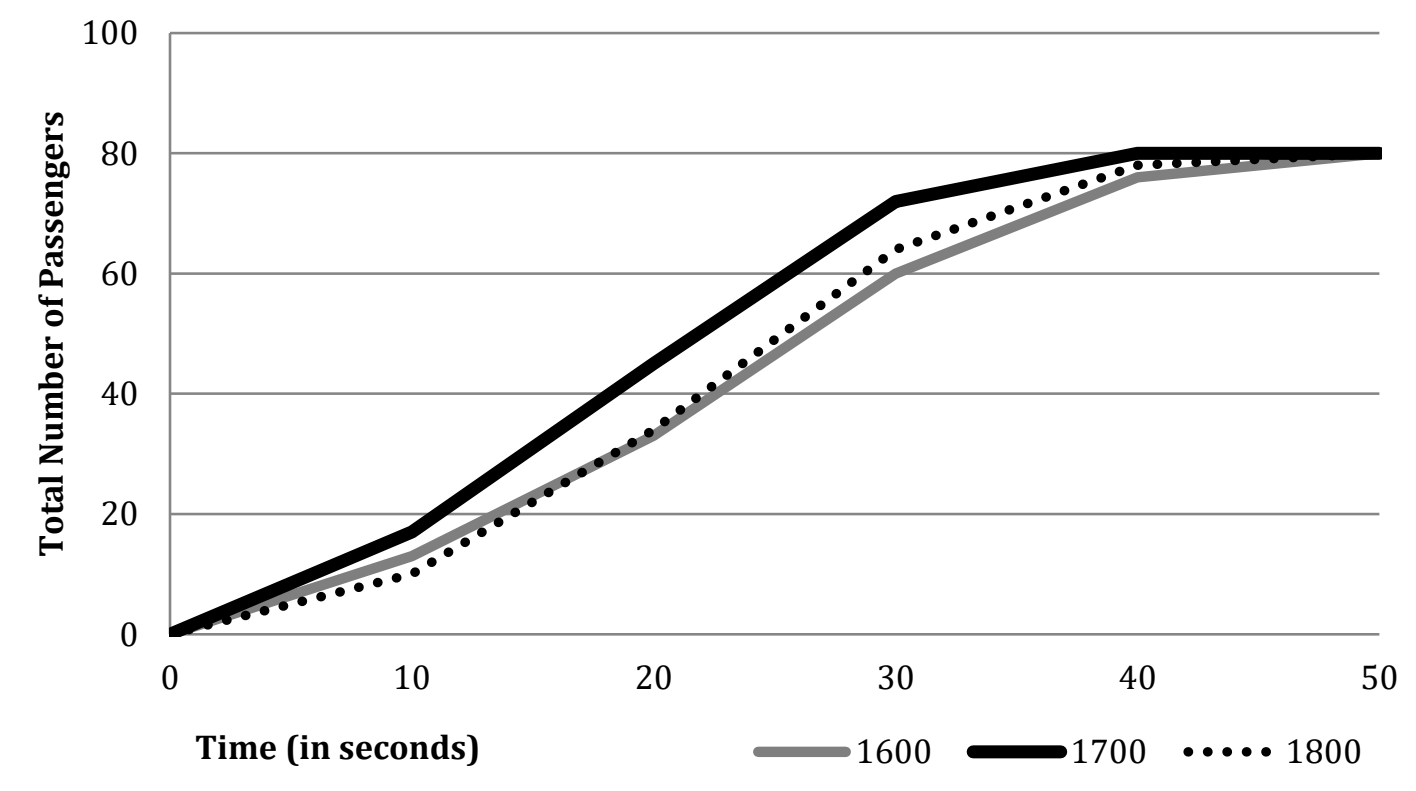

Figure 4: Cumulative number of passengers boarding or alighting throughout door open time.

In the majority alighting scenario, there was a consistent number of passenger movements every 10 seconds between 0 seconds and 30 seconds of approximately 30 people, which was only slightly lower in the first 10 seconds (see Figure 5). After 40 seconds all the passenger movements had reduced for all door widths. The widest door $(1.8 \mathrm{~m})$ performed worst in this scenario. After the doors had been open for 30 seconds, 5 more people had boarded/alighted than under the other door widths. This resulted in an approximate dwell time excess of 3 seconds for the $1.8 \mathrm{~m}$ door width for 100 passenger movements. In relation to the LOS, all cases presented a LOS = D (lower than F) for the period of time $30 \mathrm{~s}$. The $1.8 \mathrm{~m}$ reached a flow of 0.87 pass $/ \mathrm{s}-\mathrm{m}$, whilst the other door widths presented a flow between 1.03 pass $/ \mathrm{s}$ $\mathrm{m}(1.6 \mathrm{~m})$ and 0.97 pass/s-m $(1.7 \mathrm{~m})$. 


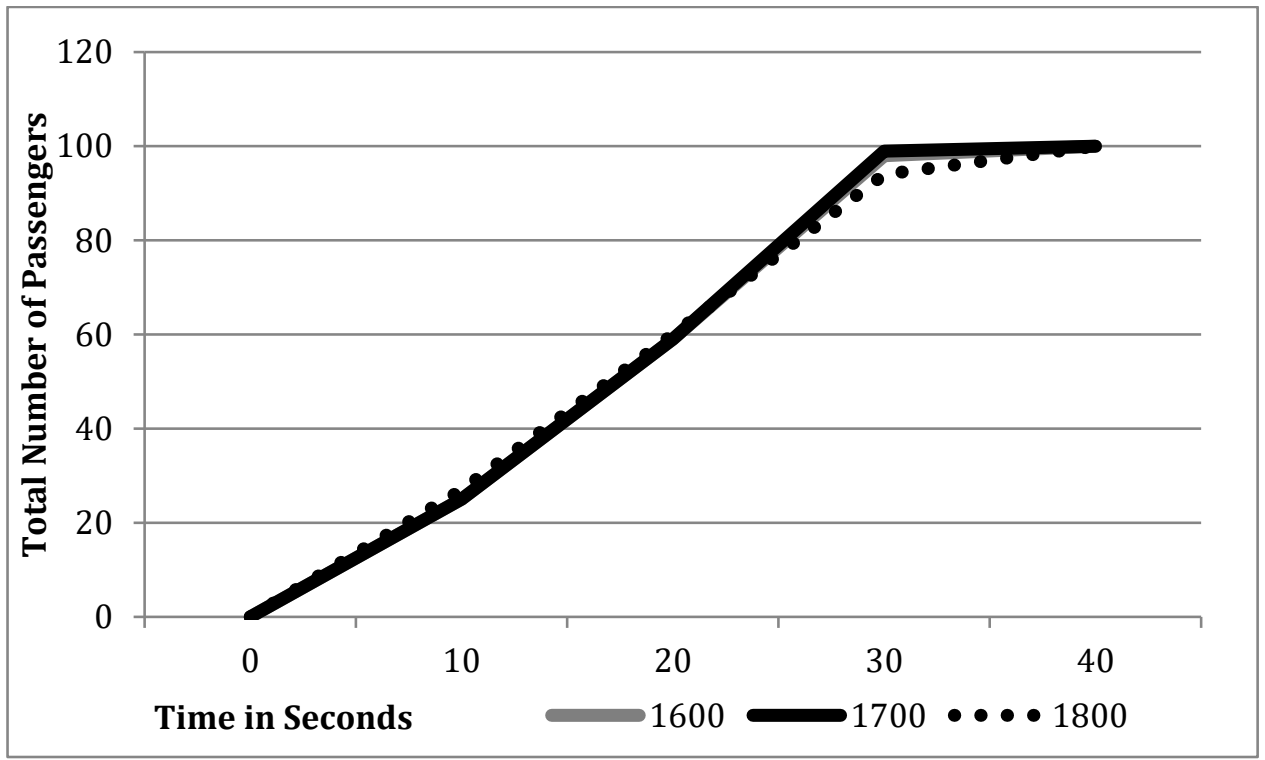

Figure 5: Cumulative number of passengers boarding or alighting throughout door open time, majority alighting scenario

In the majority boarding scenario, increasing door width increased the number of passenger movements in any given time period across this scenario (see Figure 6). After the doors have been open for 20 seconds the $1.8 \mathrm{~m}$ width door resulted in 5 more people having boarded or alighted than the $1.7 \mathrm{~m}$ width door and 10 more people than the $1.6 \mathrm{~m}$ width door. The $1.8 \mathrm{~m}$ door width had a dwell time of 46 seconds. Therefore, with each 0.1 metre increase of door width the dwell time was reduced by 3 seconds for every 100 passenger movements. In terms of flow, the $1.8 \mathrm{~m}$ reached 0.76 pass $/ \mathrm{s}-\mathrm{m}$ (LOS C) for the period of $20 \mathrm{~s}$, whilst the other width doors presented a flow between 0.85 pass $/ \mathrm{s}-\mathrm{m}$ (LOS D) and 0.73 pass $/ \mathrm{s}-\mathrm{m}$ (LOS C). However, for the $30 \mathrm{~s}$ there was no differences between $1.8 \mathrm{~m}$ and $1.7 \mathrm{~m}$ in terms of flow performance.

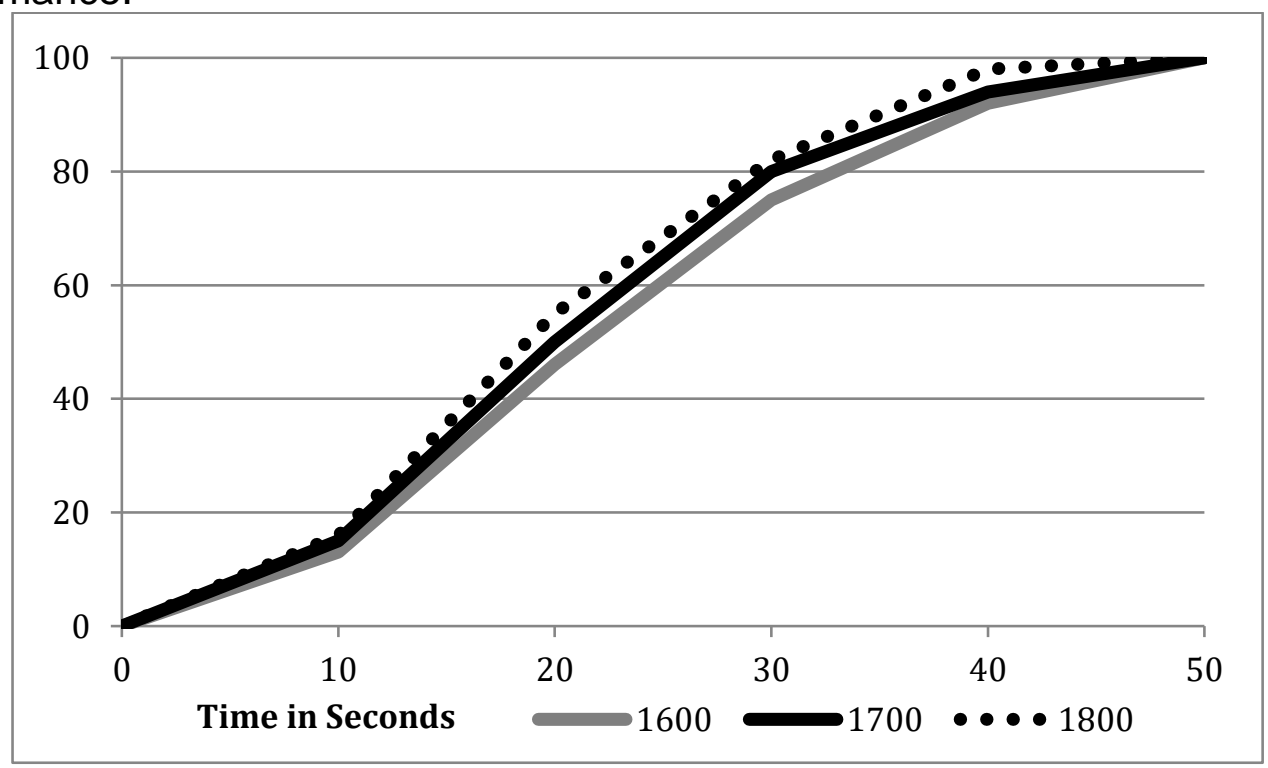


Figure 6: Cumulative number of passengers boarding or alighting throughout door open time, majority boarding scenario

As a consequence of the three scenarios, the door width $1.7 \mathrm{~m}$ presented a better performance compared to $1.6 \mathrm{~m}$ and $1.8 \mathrm{~m}$ in terms of number of passengers boarding/alighting, flow and LOS for the given conditions at PAMELA. This width was considered in the following sections when testing the standback, type of seats and use of PEDs with horizontal gap.

\subsection{Standback}

In the equal passenger boarding scenario, the $50 \mathrm{~mm}$ standback resulted in the lowest number of passenger movements but there was no difference in the number of passenger movements between the $300 \mathrm{~mm}$ and $500 \mathrm{~mm}$ standback (see Figure 7). Passenger movements were at their greatest for all standbacks between 10 seconds and 30 seconds. Passenger flow does not reach its fastest until passengers in the vestibule who are not leaving the train have created space for boarding and alighting passengers to move easily through the doors. The $300 \mathrm{~mm}$ and $500 \mathrm{~mm}$ presented a flow of 0.70 pass $/ \mathrm{s}-\mathrm{m}$ (LOS C) in the period of time $30 \mathrm{~s}$, whilst the $50 \mathrm{~mm}$ reached $0.66 \mathrm{pass} / \mathrm{s}-\mathrm{m}$ (LOS C).

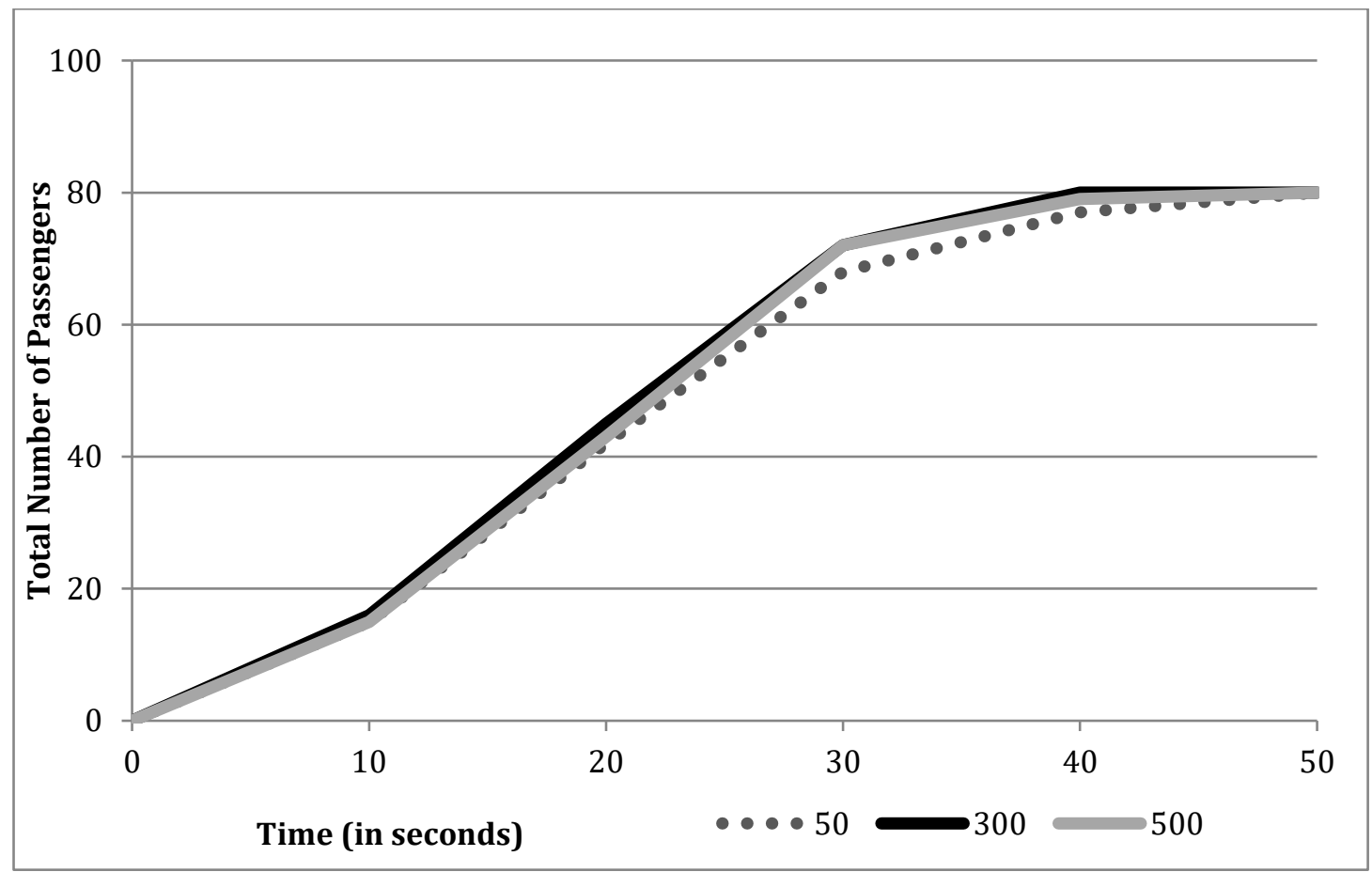

Figure 7: Cumulative number of passenger movements during the door-open time, according to standback, equal boarding/alighting scenario

In the majority alighting scenario, the $500 \mathrm{~mm}$ standback resulted in fewer passenger movements at each of the time intervals up to 30 seconds after the doors opened (see Figure 8). There was no noticeable difference between the $300 \mathrm{~mm}$ and $500 \mathrm{~mm}$ standback for passenger movements during this time, reaching 0.82 pass $/ \mathrm{s}-\mathrm{m}$ (LOS D). Whilst the $50 \mathrm{~mm}$ presented a higher flow of 0.88 pass $/ \mathrm{s}-\mathrm{m}$ with the same LOS $=\mathrm{D}$ in the segment $30 \mathrm{~s}$. 


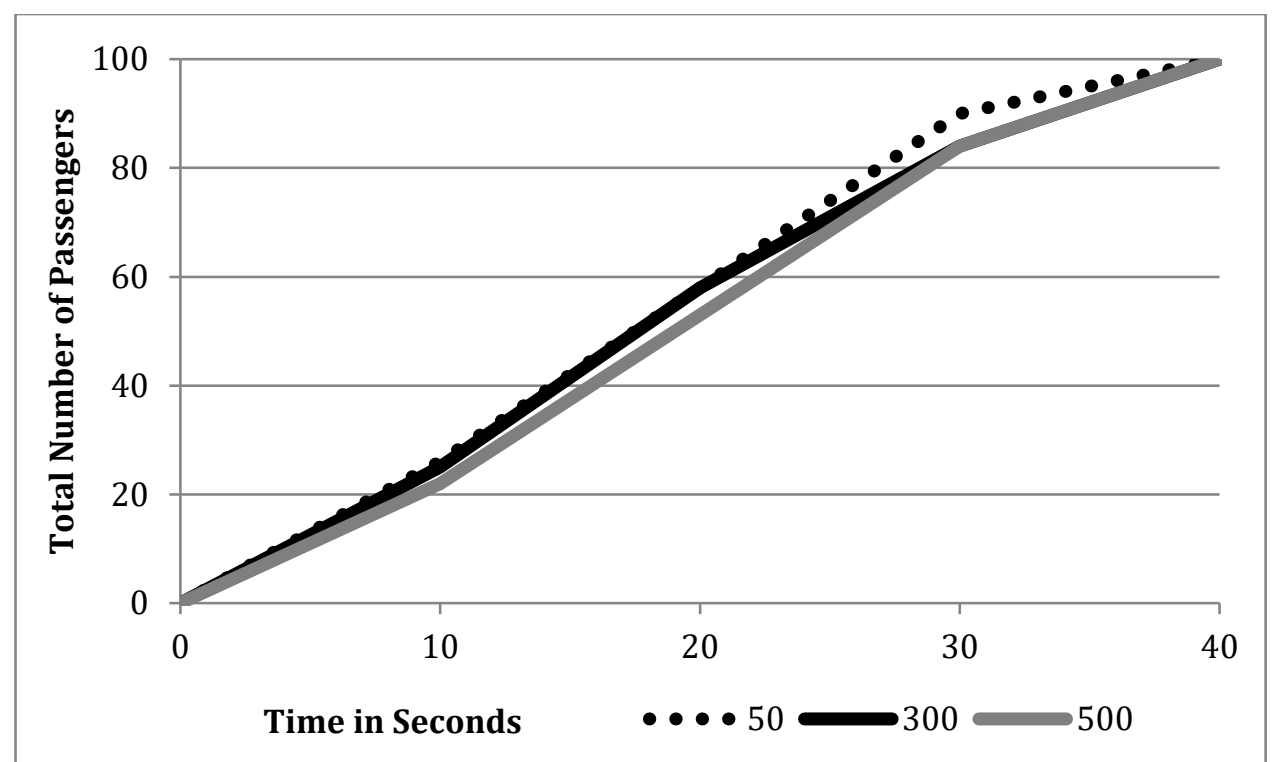

Figure 8: Cumulative number of passenger movements during the door-open time, according to standback, majority alighting scenario

In the majority boarding scenario, the largest standback $(500 \mathrm{~mm})$ performed best where boarding passengers formed the majority of passenger movement. This improvement is shown in Figure 9, which shows that after 10 seconds the $500 \mathrm{~mm}$ standback had allowed 5 more passenger movements (flow of $0.61 \mathrm{pass} / \mathrm{s}-\mathrm{m}$ or LOS C) than either the $300 \mathrm{~mm}$ standback or the $50 \mathrm{~mm}$ standback (flow of 0.47 pass/s-m or LOS B). However, after 30 seconds there was no difference between the $500 \mathrm{~mm}$ and $300 \mathrm{~mm}$ standbacks. At 40 seconds the $300 \mathrm{~mm}$ standback (flow of 0.69 pass $/ \mathrm{s}-\mathrm{m}$ or LOS C) had outperformed the $500 \mathrm{~mm}$ standback (flow of $0.66 \mathrm{pass} / \mathrm{s}-\mathrm{m}$ or LOS C). However, this is likely to be due to the fact that after 40 seconds fewer people in total were boarding or alighting. It is always the case that the final few passengers take the longest to board/alight and due to amount of passenger movement that had already occurred only the final few passengers were left in the $500 \mathrm{~mm}$ standback scenario. 


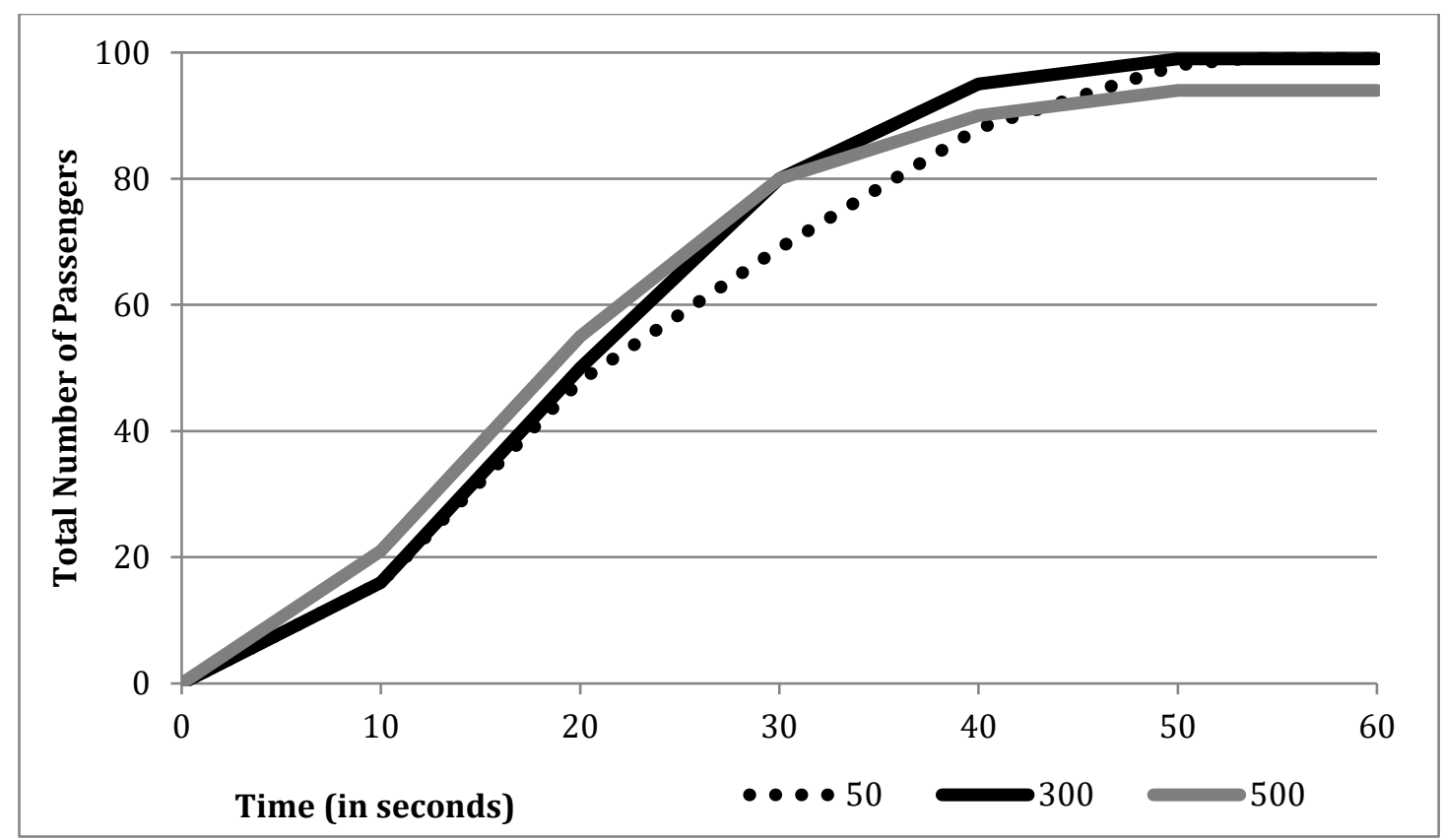

Figure 9: Cumulative number of passenger movements during the door open time for different standback arrangements, majority boarding scenario

From the different scenarios it is not clear which is the best design for the standback. In the case when there are more passengers alighting than boarding, the best performance was obtained with $50 \mathrm{~mm}$. Whilst in the other cases (more boarding than alighting or equal number of boarding and alighting) the best situation resulted between $300 \mathrm{~mm}$ and $500 \mathrm{~mm}$. All cases presented a LOS lower than F. Because of the resources involved in this research, it was not possible to select the three standback to test the following scenarios. Therefore, a $50 \mathrm{~mm}$ was used to test the seat type and the PEDs with horizontal gap, whilst a $300 \mathrm{~mm}$ was considered for the scenario to test the central pole.

\subsection{Seat Type}

In the equal passenger boarding scenario, tip-up seats performed better than perch seats across all time intervals and resulted in a dwell time reduction of almost 9 seconds. This difference peaked at 30 seconds when tip-up seats had resulted in nearly 70 passenger movements and perch seats had only resulted in 55 passenger movements.

In the majority alighting scenario (see figure 10), tip-up seats performed better than perch seats resulting in a reduced dwell time of nearly 7 seconds. At each time interval tip-up seats had greater passenger movement than perch seats with this difference peaking at 30 seconds after the doors open. In this period of time (30 s) the tip-up seats presented a flow of 0.88 pass/s-m (LOS D), whilst the perch seats reached 0.76 pass/s-m (LOS C). 


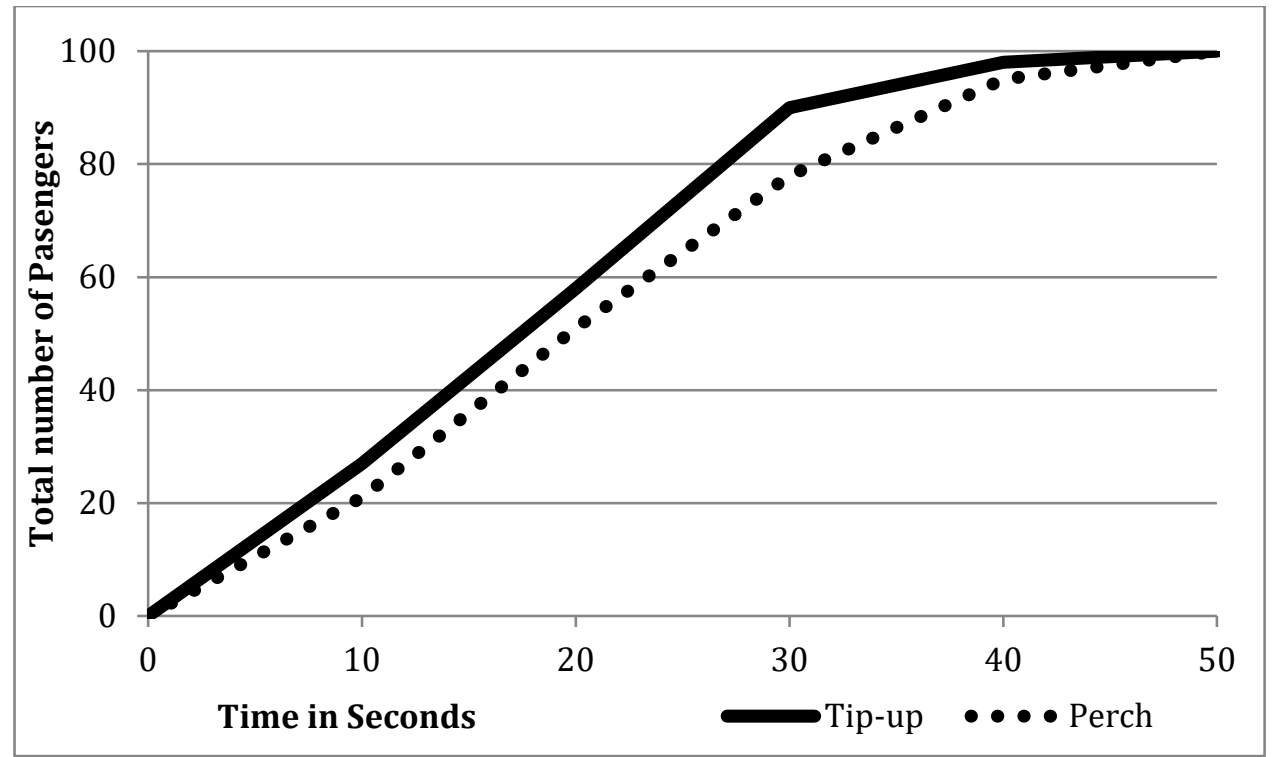

Figure 10: Cumulative number of passenger movements during the door open time for different seat types, majority alighting scenario

In the majority boarding scenario, perch seats performed best in this scenario where dwell time was reduced by 9 seconds when perch seats were present instead of tip-up seats. However, the relationship between passenger movements and seat types is a little more complicated than a simple parameter can describe; this is illustrated in Figure 11.

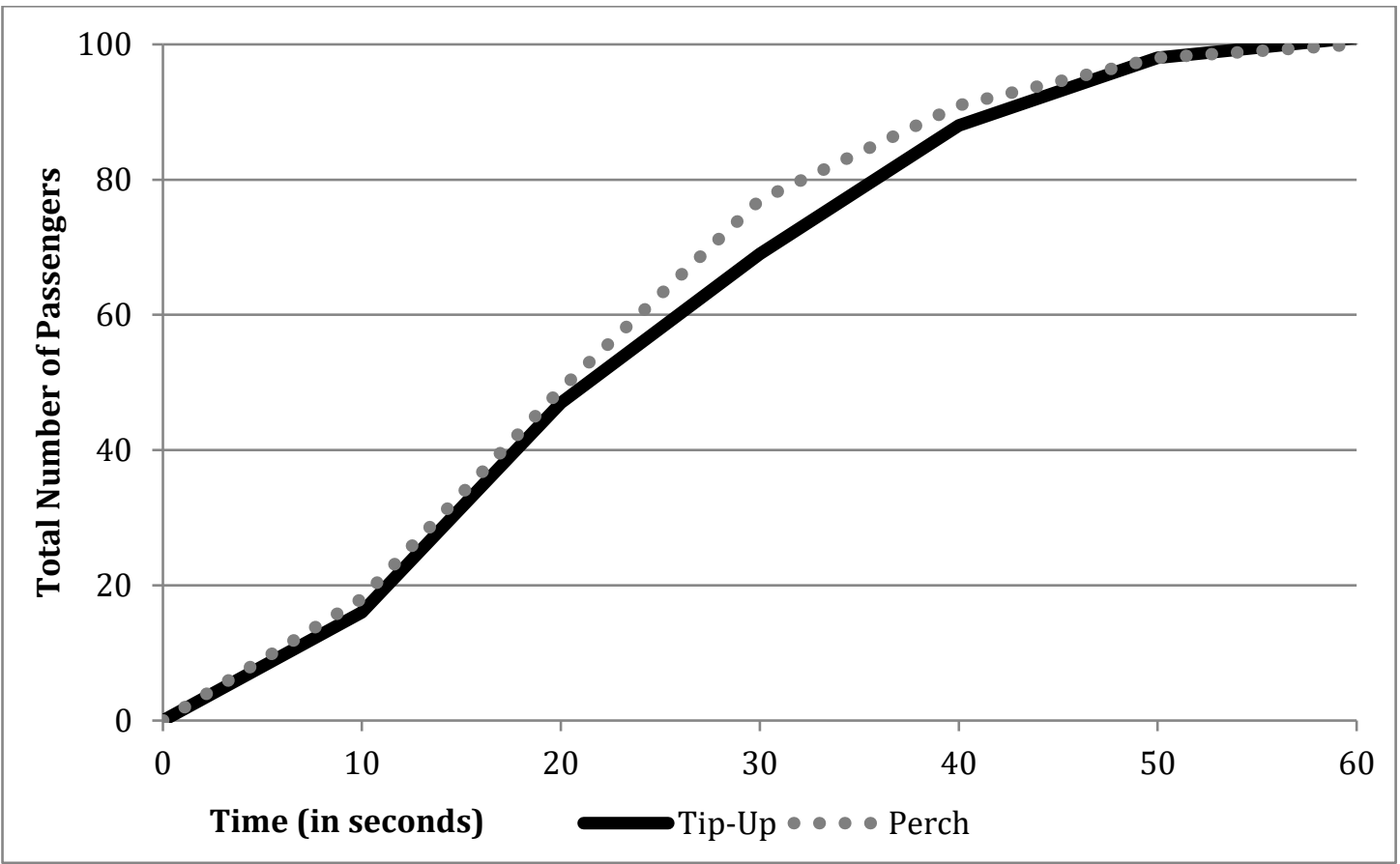

Figure 11: Cumulative number of passenger movements during the door open time for different seat types, majority boarding scenario

Figure 11 shows that perch seating results in 2 extra passenger movements up to 20 seconds after the doors have opened. This figure increases to 8 extra passenger movements after 30 seconds, in which the perch seats presented 0.75 pass/s-m (LOS C), whilst the tip-up seats reached 
0.67 pass $/ \mathrm{s}-\mathrm{m}$ (LOS C). However, the passenger movements are reduced to 3 after 40 seconds and there is no difference after 50 seconds. Therefore, while the perch seating is more advantageous than tip-up seats overall it is clear that it is most beneficial at around 30 seconds. The 30 second point occurs between 60 and 80 passenger movements and it is here that perch seats appear to offer their greatest advantage.

\subsection{Effect of Central Pole}

In neither the equal passenger boarding scenario, the majority alighting scenario or the majority boarding scenario were any differences were found in passenger movements between the presence and absence of a central vestibule pole.

\subsection{Platform Edge Doors and Horizontal Gap}

In the equal passenger boarding scenario, a smaller horizontal gap resulted in more passenger movements in any given time period and also a 4 second reduction in dwell time. After the doors had been open for 20 seconds nearly 60 passengers had boarded or alighted when the gap was $75 \mathrm{~mm}$ (flow of 0.88 pass/s-m or LOS D) compared to only 50 passengers boarding or alighting when there was a $200 \mathrm{~mm}$ gap (flow of 0.73 pass $/ \mathrm{s}-\mathrm{m}$ or LOS C). When platform edge doors were introduced with a $75 \mathrm{~mm}$ gap the rate of passenger movements decreased to a level similar to that when there was a $200 \mathrm{~mm}$ gap with no platform edge doors. However, there was no important differences in the overall passenger flow with a $200 \mathrm{~mm}$ gap between the experiments with a platform edge door and without a platform edge door.

In the majority alighting scenario, the smaller horizontal gap of $75 \mathrm{~mm}$ resulted in more passenger movements than the larger gap of $200 \mathrm{~mm}$. Identical to the equal boarding and alighting scenario when platform edge doors were introduced with a $75 \mathrm{~mm}$ gap the number of passenger movements decreased to a level similar to when there was a $200 \mathrm{~mm}$ gap with no platform edge doors. However, there was no important differences in overall passenger flow with a $200 \mathrm{~mm}$ gap between the experiments with a platform edge door and without a platform edge door.

In the majority boarding scenario, a larger horizontal gap resulted in more passenger movement across all time periods as well as a 4 second reduction in dwell time. For both horizontal gap sizes there was a reduced flow initially up to 10 seconds after the doors opened, followed by a faster flow between 10 and 30 seconds after the doors opened. After 30 seconds the flow rate dropped considerably.

When platform edge doors were introduced the passenger flow rate was only improved for the $200 \mathrm{~mm}$ gap. However, the effect of the platform edge doors did not reduce the number of passenger movements for the $75 \mathrm{~mm}$ gap. 


\section{Discussion}

It is not enough to use dwell time to measure the effectiveness of designs on passenger movement. The findings from this research show that passenger flow changes across the period of time in which the doors are open. There is a distinctive dynamic which surrounds the boarding/alighting process which indicates that there should be a point during the door-open time after which the board/alighting flow rate is characteristically much slower. This means that an additional passenger joining the passenger movement process after this point will take longer than a passenger who completed their manoeuvre earlier. Thus passenger service time is not directly proportional to the number of passengers, but depends on when during the door open time the passenger movement is being attempted. It is thus nonlinear over time. This constitutes a risk to train service reliability due to extended door-open times causing disproportionate delays to the current and subsequent trains. This gives rise to questions around transport planning and service planning issues (for example, train frequency) in order to make the best use of the dwell time for system performance as a whole.

\begin{tabular}{|l|l|l|l|}
\hline & $\begin{array}{l}\text { Equal } \\
\text { boarding/alighting }\end{array}$ & $\begin{array}{l}\text { Majority } \\
\text { Boarding }\end{array}$ & $\begin{array}{l}\text { Majority } \\
\text { Alighting }\end{array}$ \\
\hline $\begin{array}{l}\text { Door } \\
\text { Width }\end{array}$ & 1.7 & 1.8 & 1.7 \\
\hline Standback & 300 or 500 & 300 & 50 \\
\hline Seat Type & Tip-up & Perch & Tip-up \\
\hline $\begin{array}{l}\text { Central } \\
\text { Pole }\end{array}$ & No difference \\
\hline $\begin{array}{l}\text { PEDs with } \\
\text { horizontal } \\
\text { gap }\end{array}$ & Only affected with $200 \mathrm{~mm}$ horizontal gap \\
\hline
\end{tabular}

Table 2: Preferred design option by passenger scenario

In general all flow rates dropped after 30 seconds. When there were an equal number of boarders and alighters or when there was a majority of boarders a reduction in flow rate in the first 10 seconds after the doors opened occurred. Therefore optimal dynamics of passenger boarding and alighting movements occur between 10 and 30 seconds after the doors have opened.

Where there was a majority of passengers moving in one direction and it was possible for them to create two streams the dwell time was reduced. This occurred more frequently when there was not an initial mixed period of boarding and alighting. In the case of an alighting majority, when passengers were standing by the doors when they opened but were not due to alight, how they navigated a seat often affected the alighting process. This was independent of standback distance or seat type in as much as no clear pattern could be identified. 


\section{Conclusion}

Depending on whether there is a majority of passengers either boarding or alighting, different design features are optimal. None of the scenarios showed consensus on any of the design features tested. This clearly proposes a problem as different train stations and different times of day will have different numbers of passengers boarding or alighting. Operational decision making, particularly if operators have specifications as to how long the door open time will be, will determine what design features will be optimal because of the implications of operation within the station.

In terms of door width, an increased door width produced an increase in passenger flow rate. For all scenarios the narrower $1.6 \mathrm{~m}$ door width offered the worst performance in terms of dwell time. Where there was a majority passenger movement (in either direction) the $1.7 \mathrm{~m}$ door width was optimal. The mock-up used is one configuration amongst the many possibilities. In other train designs door width may have a significant effect.

Whilst there was no consensus on an optimal standback size to give a reduction in dwell time it was clear from the scenarios tested that the only size which was not the least effective for any of the scenarios was $300 \mathrm{~mm}$. Whilst a larger standback of $500 \mathrm{~mm}$ did perform well when there was equal boarding and alighting and when there was a majority of boarding, its poor performance and the loss of seats that would occur reduces its advantages. Therefore a $300 \mathrm{~mm}$ standback would be most effective across all scenarios.

Tip-up seats will result in reduced dwell times provided the limiting factor on service provision is not a station where there are consistently high numbers of alighting passengers in comparison to boarding passengers; in which case, perch seats would be recommended. The evidence for platform edge doors was mixed. Two of the scenarios found the smaller $75 \mathrm{~mm}$ horizontal gap with platform edge doors to be most effective, whereas the final scenario found the wider $200 \mathrm{~mm}$ gap with platform edge door to be most effective. When platform edge doors are not present then the horizontal gap should be limited to $75 \mathrm{~mm}$.

\section{Further Research}

Further work would allow a fuller understanding of why delays in dwell times occur when there are high numbers of people on board the train. These conditions result in considerable variability due to the nature of people avoiding each other as they attempt to board or alight the train. The role the type of seating plays in dwell time could be better understood with further, more detailed experiments and analysis. The initial investigation into passenger distributions within the carriage showed that perch seating tended to cause higher densities of people directly in front of the perch seating compared with the densities found in front of the tip-up seating There was a consistent number of people in between the fixed seating for both tip-up and perch cases, however this number is always smaller than elsewhere in the carriage.

In addition, new laboratory experiments should be conducted at PAMELA to study the effect of passengers' characteristic such as gender, 
personality, stress, culture, and personal space on the boarding and alighting times.

\section{References}

1. D'Ariano A. and Pranzo M. An advanced real-time train dispatching system for minimizing the propagation of delays in dispatching area under severe disturbances. Networks and Spatial Economics 2009; 9(1): 63-84.

2. Higgins A, Ferreira L, Kozan E. Modeling delay risks associated with train schedules. Transportation Planning and Technology 1995; 19: 89108.

3. Carey M. \& Kwiecinski A. Stochastic approximation to the effects of headways on knock-on delays of trains. Transportation Research $\mathrm{N}$ 1994; 28: 251-267

4. Higgins A, \& Kozan E. Modelling train delays in urban networks, Transportation Science 1998; 32(4): 346-357.

5. Ozekici S. \& Sengor S. On a rail transportation model with scheduled services. Transportation Science 1994; 28: 246-255.

6. Transport for London. London Underground Performance Reports. Entry and Exit Figures by Station. 2014. Accessed 8.6.15 http://data.london.gov.uk/dataset/london-underground-performancereports/resource/b6ab04fc-9062-4291-b514-7fa218073b4c

7. Buchmueller, S., Weidmann, U., \& Nash, A. (2008). Development of a dwell time calculation model for timetable planning. Computers in Railways XI, 105-114.

8. Vuchic, VR, Clarke R, \& Molinero AM. Timed transfer system planning, design and operation. No. UMTA-PA-11-0021-82-2. 1981.

9. Puong A. Dwell time model and analysis for the MBTA read line, part of MIT's Open Courseware for Public Transportation Service and Operations Planning. 2000; Available at http://www.myoops.org/twocw/mit/NR/rdonlyres/Civil-andEnvironmental-Engineering/1-258JPublic-Transportation-Service-andOperations-PlanningFall2003/D9613FBC-9279-4F31-A46D8DB2E037E9E4/0/a3_dwelltim.pdf 
10. Lin TM, Wilson NHM, Dwell Time Relationships for Light Rail Systems. Transportation Research Record 1992; 1361:287-295.

11. Transit Capacity and Quality of Service Manual 2013, Report 165, 3rd Edition, Transportation Research Board.

12. Qi Z, Baoming $\mathrm{H}$, Dewei L. Modeling and simulation of passenger alighting and boarding movement in Beijing metro stations. Transportation Research Part C 2008; 16: 635-649.

13. Heinz W. Passenger service times on trains-theory, measurements and models. Ph.D. Thesis, Royal Institute of Technology, 2003. Stockholm, Sweden.

14. Wiggenraad BL, Alighting and Boarding Times of Passengers at Dutch Railway Stations. Research Report. Trail Research School, Delft University of Technology. 2001.

15. Daamen W. Modelling passenger flow in public transport facilities. Ph.D. Dissertation, Department Transport \& Planning. 2004. Delft University Press, Netherlands.

16. Cheung CY. Lam WHK, A study of the bi-directional pedestrian flow characteristics in the Hong Kong mass transit railway stations. Journal of Transport Engineering 1997: 277-285.

17. Daly PN, McGrath F, and Annesley TJ. Pedestrian speed/flow relationships for underground stations. Traffic Engineering and Control, 1991; 75-78.

18. Weston JG, McKenna JP. London Underground Train Service Model: A description of the model and its uses, in Computer applications in railway planning and management (eds TKS Murthy et al) Comprail 1990 90, Rome

19. De Ana Rodriguez G, Seriani S, Holloway C. The impact of platform edge doors on passengers boarding and alighting time and platform behaviour. In Transportation Research Board 95th Annual Meeting 2016 (No. 16-3879).

20. Fujiyama T, Nowers J, Tyler N. Investigation into train dwell times. 2008. Submitted to the Department for Transport, United Kingdom, Available from: http://discovery.ucl.ac.uk/1363563/ 
21. Karekla X. and Tyler N. Reduced dwell times resulting from trainplatform improvements: the costs and benefits of improving passenger accessibility to metro trains, Transport Planning and Technology 2012; 35(5): 525-543.

22. Holloway C, Thoreau R, Roan T, Boampong D, Clarke T, Watts D, Tyler N. Effect of vertical step height on boarding and alighting time of train passengers. Proceedings of the Institution of Mechanical Engineers, Part F: Journal of Rail and Rapid Transit, 0954409715590480.

23. Fernandez R, Zegers P, Weber G, Tyler N. Effect of Door Width, Platform Height and Fare Collection on Bus Dwell Time. Laboratory evidence for Santiago de Chile. In Transportation Research Record 2010; 2143: 59-66.

24. Fujiyama $T$, Thoreau $R$, Tyler $N$. The Effects of the Design Factors of the Train-Platform Interface on Pedestrian Flow Rates. Pedestrian and Evacuation Dynamics 2012,Springer International Publishing, 2014; 1163-1173.

25. Fernandez R, Valencia A, Seriani S. On Passenger Saturation Flow in Public Transport Doors. Transportation Research Part A 2015; 78: 102112.

26. Seriani S, Fernandez R. Pedestrian Traffic Management of Boarding and Alighting in Metro Stations. Transportation Research Part C 2015; 53: 76-92.

27. Seriani S, Fernandez R. Planning guidelines for metro-bus interchanges by means of a pedestrian microsimulation model in Chile. Transportation Planning and Technology 2015; 38(5): 569-583.

28. Fruin J J. Designing for pedestrians: a level-of-service concept. Highway Research Record 1971; 377: 1-15. 